\title{
Torta de amendoim em substituição ao farelo de soja na alimentação de cordeiros $1 / 2$ sangue Dorper
}

\author{
Duarte, R.A.B. ${ }^{\text {; }}$ Bagaldo, A.R. ${ }^{\text {; }}$ Matoso Silva, R.V.M. ${ }^{1}$; Oliveira, R.L. ${ }^{2}$; Silva, T.M. ${ }^{2}$; Ribeiro, R. $^{2}$ e Araújo, F.L. ${ }^{1}$
}

'Universidade Federal do Recôncavo da Bahia. UFRB. Cruz das Almas. BA. Brasil.

2Universidade Federal da Bahia. UFBA. Salvador. BA. Brasil.

\section{PALAVRAS ChAVE ADICIONAIS}

Comportamento

Consumo.

Digestibilidade.

Ovinos.

\section{RESUMO}

Objetivou-se determinar o melhor nível de inclusão de torta de amendoim (Arachis hypogaea), no suplemento concentrado de cordeiros. Foram utilizados 20 cordeiros mestiços $1 / 2$ sangue Dorper, com idade média de 7 meses, mantidos em baias individuais. Os tratamentos consistiram em níveis de substituição do farelo de soja pela torta de amendoim em $0 ; 33,33 ; 66,67$; e 100\%. O período experimental foi de 32 dias, dos quais 14 dias para adaptação e 18 entre rotina e coleta de dados. Durante os últimos 5 dias experimentais foram coletadas amostras diárias do ofertado, sobras e fezes, duas vezes ao dia, as 8 e 15 horas, as quais foram secas e moídas para as análises bromatológicas. Nos $8^{\circ}, 9^{\circ} \mathrm{e}$ $10^{\circ}$ dias do período experimental, os animais foram submetidos à observação visual para avaliação do comportamento ingestivo em reposta a dieta e as respostas físiológicas dos animais ao ambiente. Nos dias $13^{\circ}, 15^{\circ}$ e $17^{\circ}$, realizou-se a medição do consumo de água em resposta a dieta oferecida. Os consumos de matéria seca, proteína bruta, nutrientes digestíveis totais, fibra em detergente neutro e fibra em detergente ácido, não foram significativos $(p>0,05)$ com a inclusão da torta de amendoim. Os coeficientes de digestibilidade da matéria seca, fibra em detergente neutro e carboidratos não fibrosos não apresentaram diferenças $(p>0,05)$ e o consumo de água foi similar $(p>0,05)$ com a inclusão da torta de amendoim em substituição ao farelo de soja. A frequência cardíaca, temperatura retal e temperatura corpórea foram semelhantes $(p>0,05)$ no período da manhã e tarde, exceto para a frequência respiratória no período da tarde que apresentou um efeito quadrático $(p<0,05)$. A torta de amendoim pode substituir totalmente o farelo de soja na alimentação de cordeiros.

\section{Groundnut cake in soybean meal replacement to the feeding of $1 \frac{1}{2}$ Dorper lambs}

\section{SUMMARY}

The objective was to determine the best level of groundnut cake (Arachis hypogaea) in concentrate supplement for lambs. We used 20 crossbred lambs 1/2 Dorper, with a mean age of 7 months, kept in individual pens. Treatments consisted of substitution levels of soybean meal peanut pie: $0,33.33,66.67$, and $100 \%$. The experimental period was 32 days, including 14 days for adaptation and 18 between routine and data collection. During the last 5 days of experimental samples were collected daily offered, orts and feces, twice daily, at 8 and 15 hours. In the $8^{\text {th }}, 9^{\text {th }}$ and $10^{\text {th }}$ days of the experimental period, the animals underwent evaluation for visual observation of ingestive behavior in response to diet and physiological responses of animals to the environment. On days 13,15 and 17, held the measurement of water consumption in response to diet offered. For the consumption of dry matter, crude protein, NDT, neutral detergent fiber and acid detergent fiber not significant differences $(p>0.05)$ were observed with the inclusion of groundnut cake. The digestibility of DM, NDF and CNF showed no differences ( $p>0.05)$, and water consumption was similar $(p>0.05)$ with the inclusion of groundnut cake instead of soybean meal. The heart rate (FC), rectal temperature (TR) and body temperature (TC) were similar $(p>0.05)$ in the morning and afternoon, except for respiratory rate in the afternoon that showed a quadratic effect $(p<0.05)$. The groundnut cake can totally replace soybean meal in the diet of lambs.

jetivo do rebanho é a produção de carne, é necessário um aporte maior de proteína e energia nas dietas, logo é necessária à adição de concentrado que eleva o custo com alimentação.

Dentre os coprodutos da agroindústria, com potencial de uso na alimentação de ruminantes, destacam-se aqueles oriundos da produção de biodiesel (Lage et al., 2012).
Os ovinos como os demais ruminantes, possuem dieta a base de volumosos, no entanto, quando o ob- 
Com isso, as tortas oleaginosas proveniente da produção do biodiesel surgem como alimentos alternativos para substituição do milho e a soja, por exemplo, na formulação do concentrado, e estão sendo testados como opção de minimizar os custos.

A utilização de alimentos menos onerosos é bastante viável para melhorar o efeito custo/beneficio podendo obter o desempenho animal satisfatório. Segundo Santos et al., 2012, as tortas e farelos apresentam grande potencial como fontes alimentares alternativas, principalmente de ruminantes, uma vez que possuem consideráveis concentrações de proteína e extrato etéreo, caracterizando-as como alimentos protéicos e/ou energéticos.

O amendoim é uma importante fonte de matériaprima para a produção do biodiesel, que após a extração do óleo, obtém-se a torta, um coproduto com características nutritivas adequadas para ser empregado na composição das dietas para animais que demandam de elevados teores de proteína. Entretanto, a torta de amendoim de qualidade, depende em geral da qualidade das sementes e do método de extração do óleo, mas em geral apresentam elevados teores de nitrogênio e de nutrientes digestíveis, semelhantes ao farelo de soja (Abdalla et al., 2008).

Alimentos alternativos devem ser avaliados quanto aos efeitos adversos ou positivos que eventualmente podem ocorrer sobre os animais que os consomem, principalmente em regiões tropicais. Portanto, objetivou-se avaliar o consumo, a digestibilidade dos nutrientes, comportamento ingestivo e os parâmetros fisiológicos de cordeiros alimentados com torta de amendoim em substituição ao farelo de soja na dieta.

\section{MATERIAL E MÉTODOS}

Foram utilizados 20 cordeiros, mestiços $1 / 2$ sangue Dorper, machos inteiros, com idade inicial de 7 meses, com peso de $20,70 \pm 3,18 \mathrm{~kg}$, confinados em baias individuais de $1 \mathrm{~m}^{2}$, contendo comedouros, bebedouros e saleiros. Durante o período pré-experimental, os animais foram identificados, pesados, vermifugados, vacinados e distribuídos em delineamento inteiramente casualizado de acordo com os tratamentos. O período experimental foi de 32 dias, sendo 14 dias de adaptação dos animais às dietas experimentais e às instalações e 18 dias de coletas.

Os tratamentos foram compostos de $0 ; 33,33 ; 66,67$ e $100 \%$ de substituição do farelo de soja pela torta de amendoim no concentrado. As dietas totais foram composta por feno de tifton 85 e concentrado (farelo de soja, torta de amendoim, farelo de milho, ureia e premix mineral) na proporção de 50:50.

Os alimentos foram oferecidos às $9 \mathrm{~h}$ e às $16 \mathrm{~h}$, na forma de mistura completa, com controle diário da quantidade fornecida, ajustando em $10 \%$ de sobras. As amostras dos alimentos fornecidos e das sobras destes foram pesadas, coletadas durante o $28^{\circ}$ ao $32^{\circ}$ dia acondicionadas em sacos plásticos, identificadas, e armazenadas em freezer a $-20^{\circ} \mathrm{C}$ para posteriores análises.
Tabela I. Composição bromatológica dos ingredientes utilizados nas dietas experimentais de cordeiros $1 / 2$ Dorper submetidos às dietas com substituição de farelo de soja pela torta de amendoim (Chemical composition of the ingredients used in the experimental diets $1 / 2$ Dorper lambs which were fed with replacement of soybean meal with groundnut cake).

\begin{tabular}{lrrrr}
\hline \multirow{2}{*}{ Item } & \multicolumn{4}{c}{ Ingrediente } \\
\cline { 2 - 5 } & GMM & \multicolumn{1}{c}{ FS } & \multicolumn{1}{c}{ TA } & FT-85 \\
\hline Matéria seca (\%) $^{\prime} 92,50$ & 88,72 & 88,54 & 85,02 \\
Matéria mineral $^{1}$ & 1,40 & 6,56 & 6,46 & 7,91 \\
Proteína bruta $^{1}$ & 7,45 & 47,76 & 46,45 & 5,87 \\
Extrato etéreo $^{1}$ & 5,11 & 3,45 & 10,83 & 2,02 \\
Fibra em detergente neutro $^{1,2}$ & 14,87 & 11,05 & 13,47 & 73,58 \\
Fibra em detergente ácido $^{1}$ & 6,05 & 10,28 & 9,20 & 40,70 \\
PIDN $^{1}$ & 1,62 & 62,5 & 3,01 & 5,53 \\
PIDA $^{\text {Lignina }}{ }^{1}$ & 0,91 & 0,29 & 0,11 & 1,26 \\
Celulose $^{1}$ & 2,18 & 1,96 & 4,90 & 8,05 \\
Hemicelulose $^{1}$ & 3,87 & 8,32 & 4,30 & 32,65 \\
Carboidratos não fibrosos $^{1}$ & 8,82 & 0,77 & 4,26 & 32,88 \\
Nutrientes digestíveis totais $^{1,3}$ & 85,17 & 31,18 & 22,80 & 10,61 \\
& 85 & 79,84 & 86,40 & 48,67 \\
\hline
\end{tabular}

${ }^{1}$ Valor expresso em \% da matéria seca. ${ }^{2}$ Corrigido para cinzas e proteína. PIDN= Proteína insolúvel em detergente neutro. PIDA= Proteína insolúvel em detergente ácido, ${ }^{3}$ Valores estimados com base na nas equações do NRC (2001). GMM= Grão de milho moído; FS= Farelo de soja; TA= Torta de amendoim; FT-85= Feno de Tifton-85.

As amostras dos alimentos e das sobras foram submetidas à pré-secagem a $55^{\circ} \mathrm{C}$, durante 72 horas, moídas em moinho de faca tipo Willey com peneira de 1 $\mathrm{mm}$ e armazenadas em sacos plásticos, devidamente lacrados, para análises laboratoriais. Nas amostras pré-secas, foram determinados os teores de matéria seca (MS), matéria mineral (MM), proteína bruta (PB), extrato etéreo (EE), proteína insolúvel em detergente neutro (PIDN) e proteína insolúvel em detergente ácido (PIDA) de acordo com os procedimentos da AOAC (1990). As determinações de fibra em detergente neutro (FDN), fibra em detergente ácido (FDA), hemicelulose, celulose e lignina de acordo a metodologia de Van Soest et al. (1991).

Os carboidratos totais (CT) foram calculados pela fórmula $\mathrm{CT}=100-(\mathrm{PB}+\mathrm{EE}+\mathrm{MM})$ e os não-fibrosos (CNF), que constituem as frações A e B1, foram obtidos pela fórmula CNF=CT -FDNcp, (Sniffen et al., 1992).

Os teores de NDT foram calculados conforme as fórmulas de estimativas da digestibilidade de cada fração analítica (NRC, 2001):

$$
\mathrm{NDT}=\mathrm{PBD}+(2,25 \times \mathrm{EED})+\mathrm{FDND}+\mathrm{CNFD}
$$

As dietas foram formuladas para serem isonitrogenadas (16\%PB), segundo o NRC (1994), conforme apresentado na tabelas I e II.

A estimativa da digestibilidade foi determinada pela coleta total de fezes, com o uso de bolsas coletoras. As fezes foram pesadas, armazenadas e identificadas em amostra composta por animal, no período do $28^{\circ}$ ao $32^{\circ}$ dias. 
Tabela II. Proporção dos ingredientes e composição bromatológica das dietas experimentais utilizadas na alimentação de ovinos $1 / 2$ Dorper submetidos à dietas substituição de farelo de soja pela torta de amendoim (Proportion of ingredients and chemical composition of experimental diets fed to Dorper $1 / 2$ submitted to diets replacing soybean meal with groundnut cake).

\begin{tabular}{lrrrr}
\hline \multirow{2}{*}{ Ingrediente (\% MS) } & \multicolumn{4}{c}{ Nível de substituição } \\
\cline { 2 - 5 } & 0,00 & 33,33 & 66,67 & 100,00 \\
\hline Farelo de milho & 27,00 & 27,00 & 27,00 & 27,00 \\
Farelo de soja & 21,00 & 14,00 & 7,00 & 0,00 \\
Torta de amendoim & 0,00 & 7,00 & 14,00 & 21,00 \\
Premix mineral & 1,50 & 1,50 & 1,50 & 1,50 \\
Uréia & 0,50 & 0,50 & 0,50 & 0,50 \\
Feno de Tifton-85 & 50,00 & 50,00 & 50,00 & 50,00 \\
\hline Composição bromatológica (\% MS) & & & \\
\hline Matéria seca (\%) & 88,10 & 88,09 & 88,07 & 88,06 \\
Matéria mineral & 7,21 & 7,20 & 7,19 & 7,19 \\
Proteína bruta & 16,38 & 16,29 & 16,20 & 16,11 \\
Extrato etéreo & 3,12 & 3,63 & 4,15 & 4,67 \\
Fibra em detergente neutro & 43,13 & 43,30 & 43,46 & 43,63 \\
Fibra em detergente ácido & 24,14 & 24,07 & 23,99 & 23,92 \\
PIDN (\% PB) & 33,36 & 33,13 & 32,91 & 32,68 \\
PIDA (\% PB) & 9,37 & 9,25 & 9,13 & 9,00 \\
Lignina & 5,02 & 5,23 & 5,44 & 5,64 \\
Celulose & 19,12 & 18,84 & 18,56 & 18,27 \\
Hemicelulose & 18,98 & 19,23 & 19,47 & 19,72 \\
Carboidratos não fibrosos & 31,07 & 30,48 & 29,90 & 29,31 \\
Nutrientes digestíveis totais ${ }^{1}$ & 64,17 & 64,62 & 65,08 & 65,54 \\
\hline
\end{tabular}

${ }^{1}$ Valores estimados com base na nas equações do NRC (2001).

A estimativa do consumo de nutrientes digestíveis totais foi obtida a partir da diferença entre o ingerido e o recuperado nas fezes de todos os nutrientes, com base na matéria seca, conforme Sniffen et al. (1992):

$\mathrm{CNDT}(\mathrm{kg} / \mathrm{dia})=(\mathrm{PBi}-\mathrm{PBf})+2,25^{*}(\mathrm{EEi}-\mathrm{EEF})+(\mathrm{CFi}-\mathrm{CFf})$

Em que os índices i e f correspondem ao ingerido e excretado nas fezes.

Os cálculos dos coeficientes de digestibilidade da MS, PB, EE, FDN e CNF foram efetuados segundo fórmula, $\mathrm{DAP}=$ (ofertado-sobras) - fezes/ofertado-sobras $\times 100$.

No oitavo e nono dia do período experimental, os animais foram submetidos à observação visual para avaliação do comportamento ingestivo. Os animais foram observados a cada 5 minutos, durante 48 horas, para determinação do tempo despendido com alimentação, ruminação e ócio (Johnson e Combs, 1991).

Foram ofertados 6 litros de água para cada animal e diariamente foi medido o consumo através de uma proveta graduada nos $13^{\circ}, 15^{\circ}$ e $17^{\circ}$ dias.

$\mathrm{O}$ termohigrômetro e o globotermômetro foram instalados com o intuito de medir as temperaturas e umidade do ar, em que o globo foi instalado a 1,70 m do solo para obtenção do calor radiante. O monitoramento do ambiente foi realizado no décimo dia do período, durante 12 horas, a cada hora, determinando a temperatura local, a umidade relativa do ar e a ra-
Tabela III. Valores médios das variáveis ambientais observadas durante o experimento (Mean values of environmental variables observed during the experiment).

\begin{tabular}{|c|c|c|c|}
\hline Variáveis & Manhã & Tarde & Média geral \\
\hline Temperatura do ar $\left({ }^{\circ} \mathrm{C}\right)$ & 25,2 & 26,7 & 25,95 \\
\hline Umidade relativa do ar (\%) & 80 & 69 & 74,5 \\
\hline $\begin{array}{l}\text { Índice de temperatura do } \\
\text { globo negro e umidade (\%) }\end{array}$ & 25 & 27 & 26 \\
\hline $\begin{array}{l}\text { Índice de temperatura e } \\
\text { umidade }(\%)\end{array}$ & 30 & 31,5 & 30,75 \\
\hline
\end{tabular}

diação solar. A partir dos dados das temperaturas do bulbo seco e úmido foi calculada a umidade relativa do ar expressa em pressão parcial de vapor, que representa a pressão exercida pelo conteúdo de vapor d'água na atmosfera não saturada, que influencia diariamente as trocas térmicas por evaporação. Os cálculos foram determinados a partir da equação:

$$
\operatorname{Pp}(\mathrm{ta})=\mathrm{Os}(\mathrm{tu})-\mu(\mathrm{ta}-\mathrm{tu})
$$

Onde:

$\mathrm{Pp}(\mathrm{ta})=$ pressão parcial de vapor à temperatura do ar;

Ps $(\mathrm{tu})=$ Pressão de saturação à temperatura tu;

$\mu=$ constante psicrométrica, $\mathrm{KPa} /{ }^{\circ} \mathrm{C}$;

ta $=$ temperatura do ar ou do bulbo seco, ${ }^{\circ} \mathrm{C}$;

$\mathrm{tu}=$ temperatura do bulbo úmido, ${ }^{\circ} \mathrm{C}$ (Buffington $e t$ al., 1981).

Com as temperaturas do globotermômetro foi calculado o Índice de Temperatura do Globo e Umidade (ITGU), desenvolvido por Buffington et al. (1981), através da seguinte expressão:

$$
\text { ITGU }=\operatorname{tg}+0,36 \mathrm{tpo}+41,5 \mu
$$

Onde:

ITGU = índice de temperatura do globo e umidade;

$\mathrm{Tg}=$ temperatura do termômetro de globo ${ }^{\circ} \mathrm{C}$;

$\mathrm{Tpo}=$ temperatura do ponto de orvalho, ${ }^{\circ} \mathrm{C} \mathrm{e}$

$41,5=$ constante (tabela III).

Em cada animal foi medido a frequência respiratória (através de movimentos do flanco/minuto) com o auxílio de um cronômetro por período de 15 segundos e o resultado multiplicado por quatro para obtenção em minutos. A frequência cardíaca foi obtida através do estetoscópio colocado diretamente na região torácica esquerda. A temperatura retal foi aferida através de termômetros clínicos digitais. A temperatura superficial (TS) foi obtida com o auxilio de termômetro infravermelho digital em quatro pontos determinados do corpo do animal: membro anterior direito (MAD), membro anterior esquerdo (MAE), membro posterior direito (MPD), membro posterior esquerdo (MPE). Os dados de frequência respiratória, frequência cardíaca, temperatura superficial e temperatura retal foram coletados de 8:00 às 9:00 horas e de 15:00 ás 16:00 horas no $10^{\circ}$ dia do período experimental. 
Tabela IV. Consumo diário de nutrientes em gramas/ dia, por cordeiros alimentados com dietas contendo torta de amendoim em substituição ao farelo de soja (Daily nutrient intake in grams, for lambs fed diets containing groundnut cake instead of soybean meal).

\begin{tabular}{|c|c|c|c|c|c|c|}
\hline \multirow{2}{*}{ Itens } & \multicolumn{4}{|c|}{ Níveis de substituição } & \multirow{2}{*}{$\mathrm{CV}(\%)$} & \multirow{2}{*}{ Eq. regressão } \\
\hline & 0,00 & 33,33 & 66,67 & 100,00 & & \\
\hline MS & 1308,68 & 1290,12 & 1216,52 & 1277,67 & 18,97 & $\hat{Y}^{n s}=1273,24$ \\
\hline PB & 218,48 & 203,61 & 200,56 & 210,07 & 14,86 & $\hat{Y}^{n s}=208,18$ \\
\hline FDN & 431,83 & 241,97 & 232,62 & 243,29 & 14,78 & $\hat{Y}^{n s}=422,84$ \\
\hline EE & 45,29 & 52,29 & 59,29 & 66,29 & 16,20 & $\hat{Y}=0,21 X+45,29$ \\
\hline LDA & 55,46 & 57,85 & 57,88 & 63,80 & 14,86 & $\hat{Y}^{n s}=58,75$ \\
\hline CEL & 196,90 & 184,13 & 174,74 & 179,48 & 15,06 & $\hat{Y}^{n s}=183,81$ \\
\hline HEM & 179,47 & 176,92 & 178,18 & 186,49 & 15,00 & $\hat{Y}^{n s}=180,27$ \\
\hline CNF & 461,44 & 424,13 & 413,15 & 423,90 & 15,73 & $\hat{Y}^{n s}=430,65$ \\
\hline NDT & 1217,59 & 1161,16 & 1152,47 & 1217,66 & 14,82 & $\hat{Y}^{n s}=1187,22$ \\
\hline Água & 2620 & 2080 & 2400 & 2470 & 31,38 & $\hat{Y}^{n s}=2,39$ \\
\hline \multicolumn{7}{|c|}{ Consumo (\% PC) } \\
\hline MS & 5,40 & 5,33 & 4,97 & 5,25 & 16,94 & $\hat{Y}^{n s}=5,24$ \\
\hline PB & 0,90 & 0,84 & 0,82 & 0,87 & 14,69 & $\hat{Y}^{n s}=0,86$ \\
\hline FDN & 1,79 & 1,73 & 1,68 & 1,78 & 14,81 & $\hat{Y}^{n s}=1,75$ \\
\hline EE & 0,18 & 0,51 & 0,85 & 1,18 & 63,29 & $\hat{Y}=0,01 X+0,18$ \\
\hline CNF & 1,91 & 1,76 & 1,69 & 1,75 & 15,91 & $\hat{Y}^{n s}=1,77$ \\
\hline NDT & 5,04 & 4,81 & 4,72 & 5,03 & 14,87 & $\hat{Y}^{n s}=4,90$ \\
\hline \multicolumn{7}{|c|}{ Consumo (g/UTM) } \\
\hline MS & 119,48 & 118,06 & 110,17 & 116,45 & 16,05 & $\hat{Y}^{n s}=116,04$ \\
\hline PB & 20,01 & 18,66 & 18,18 & 19,23 & 13,05 & $\hat{Y}^{\mathrm{ns}}=19,02$ \\
\hline FDN & 39,55 & 38,32 & 37,31 & 39,40 & 13,20 & $\hat{Y}^{n s}=38,64$ \\
\hline EE & 4,14 & 4,81 & 5,47 & 6,14 & 16,74 & $\hat{Y}=0,02 X+4,14$ \\
\hline CNF & 111,42 & 106,41 & 104,57 & 111,55 & 13,19 & $\hat{Y}^{n s}=108,49$ \\
\hline NDT & 42,18 & 38,94 & 37,47 & 38,83 & 14,29 & $\hat{Y}^{n s}=39,35$ \\
\hline
\end{tabular}

$\mathrm{CV}=$ Coeficiente de variação; $\mathrm{MS}=$ matéria seca; $\mathrm{PB}=$ proteína bruta; FDN= fibra em detergente neutro; LDA= lignina em detergente ácido; $\mathrm{CEL}=$ celulose; $\mathrm{HEM}=$ hemicelulose; $\mathrm{CNF}=$ carboidratos não fibrosos; $\mathrm{NDT}=$ nutrientes digestíveis totais; $\mathrm{PC}=$ peso corporal; $\mathrm{UTM}=$ unidade de tamanho metabólico. ${ }^{\text {ns}}=$ não significativa.

O delineamento utilizado foi o inteiramente casualizado e os resultados de consumo, digestibilidade, parâmetros fisiológicos e metabólicos foram submetidos à análise de variância e regressão ao nível de 5\% de significância, em função dos níveis de substituição do farelo de soja pela torta de amendoim.

\section{RESULTADOS E DISCUSSÃO}

A substituição do farelo de soja pela torta de amendoim não proporcionou efeito $(p>0,05)$ no consumo de matéria seca em gramas/dia, \% do peso corporal (PC) e $\mathrm{g}$ / unidade de tamanho metabólico (UTM) (tabela IV). Esses resultados sugerem que além das dietas estarem semelhantes em sua composição, com exceção do EE e que atenderam suas demandas, ocorreu também uma boa aceitabilidade pelos animais com a presença da torta de amendoim na dieta. Embora os teores de EE tenham aumentado, com o aumento dos níveis de torta de amendoim, não chegaram a ultrapassar os níveis de $7 \%$, como recomendado nas dietas para ruminantes (Vasconcelos and Galyean, 2007), o que colaborou para que o consumo de matéria seca não fosse influenciado. Possivelmente a similaridade nos teores de FDN das dietas e o tamanho de partículas pequeno e semelhante entre as dietas também resultou em consumos de MS iguais.

O consumo de água foi similar $(\mathrm{p}>0,05)$ entre as dietas (tabela IV) e superiores ao preconizado pelo (NRC, 1994) que sugerem $0,800 \mathrm{~kg}$ de água/dia. No presente trabalho, os animais obtiveram consumo médio de aproximadamente $2 \mathrm{~kg}$ de água/dia . Esse maior consumo médio, comparado ao NRC, pode ser devido a utilização de feno na dieta, que estimula a ingestão de água, como também a temperatura média nas instalações. O consumo em g/dia, \%PC e g/UTM semelhantes $(p>0,05)$ de $P B$, pode ser explicado pelo fato das dietas serem isonitrogenadas, uma vez que o consumo de MS não foi diferente com as substituições de farelo de soja pela torta de amendoim.

Forbes (1995) e Van Soest (1994), afirmaram que dietas pobres em nitrogênio reduzem o consumo, esse fato está associado às concentrações de $\mathrm{PB}$ abaixo de $7 \%$, causando efeitos adversos. Contudo neste estudo as dietas foram balanceadas em $16 \%$ de $\mathrm{PB}$, suprindo as necessidades dos animais.

Os consumos de fibra em detergente neutro (FDN) em g/dia, \%PC e g/UTM foram semelhantes $(p>0,05)$, resultado esperado, uma vez que as dietas apresenta- 
Tabela V. Digestibilidade (\%) da matéria seca (MS), fibra em detergente neutro (FDN), carboidratos não fibrosos (CNF), de acordo com os níveis de torta de amendoim (Digestibility (\%) of dry matter (MS), neutral detergent fiber (FDN), non-fiber carbohydrates (CNF), according to the levels of groundnut cake).

\begin{tabular}{|c|c|c|c|c|c|c|}
\hline \multirow{2}{*}{ Itens } & \multicolumn{4}{|c|}{ Níveis de substituição } & \multirow{2}{*}{$\mathrm{CV}(\%)$} & \multirow{2}{*}{ Eq. regressão } \\
\hline & 0,00 & 33,33 & 66,67 & 100,00 & & \\
\hline MS & 79,32 & 77,90 & 77,01 & 78,44 & 2,90 & $\hat{Y}^{n s}=78,17$ \\
\hline FDN & 62,22 & 60,84 & 60,14 & 61,71 & 10,06 & $\hat{Y}^{n s}=61,23$ \\
\hline PB & 84,45 & 81,59 & 80,96 & 82,55 & 1,84 & $\hat{Y}=0,001 X^{2}-0,1189 X+84,45$ \\
\hline EE & 92,52 & 93,52 & 94,52 & 95,52 & 1,37 & $\hat{Y}=0,03 X+92,52$ \\
\hline CNF & 96,10 & 95,33 & 93,55 & 94,85 & 2,61 & $\hat{Y}^{n s}=94,96$ \\
\hline
\end{tabular}

$C V=$ Coeficiente de variação. ${ }^{\text {ns}=~ n a ̃ o ~ s i g n i f i c a t i v a . ~}$

Tabela VI. Comportamento ingestivo de ovinos em confinamento, no período de 24 horas, frequência respiratória (FR), temperatura retal (TR), frequência cardíaca em batimentos por minuto (FC) e temperatura corporal (TC) de ovinos alimentados com torta de amendoim oriunda da produção de biodiesel em substituição ao farelo de soja (Feeding behavior of confinement in sheep, in 24-hour period, respiratory rate (RR), rectal temperature (RT), heart rate in beats per minute (HR) and body temperature (TC) of sheep fed with pie groundnut derived from biodiesel production to replace soybean meal).

\begin{tabular}{|c|c|c|c|c|c|c|}
\hline \multirow{2}{*}{ Itens } & \multicolumn{4}{|c|}{ Níveis de substituição } & \multirow{2}{*}{$\mathrm{CV}(\%)$} & \multirow{2}{*}{ Eq. regressão } \\
\hline & 0,00 & 33,33 & 66,67 & 100,00 & & \\
\hline \multicolumn{7}{|c|}{24 horas } \\
\hline Ingestão (min) & 295,00 & 260,00 & 320,00 & 281,00 & 14,07 & $\hat{Y}^{n s}=289,00$ \\
\hline Ócio (min) & 667,50 & 732,00 & 623,00 & 659,00 & 11,66 & $\hat{Y}^{n s}=670,35$ \\
\hline Ruminação (min) & 480,00 & 450,50 & 499,50 & 502,50 & 14,33 & $\hat{Y}^{\mathrm{ns}}=483,12$ \\
\hline \multicolumn{7}{|c|}{ Manhã } \\
\hline $\mathrm{FR}(\mathrm{r} / \mathrm{min})$ & 58,48 & 48,80 & 48,80 & 35,20 & 45,38 & $\hat{Y}^{n s}=47,80$ \\
\hline $\operatorname{TR}\left({ }^{\circ} \mathrm{C}\right)$ & 38,92 & 38,72 & 39,56 & 38,90 & 0,86 & $\hat{Y}^{n s}=38,78$ \\
\hline FC (bat/min) & 108,00 & 97,60 & 92,00 & 96,80 & 19,07 & $\hat{Y}^{n s}=98,60$ \\
\hline $\operatorname{TC}\left({ }^{\circ} \mathrm{C}\right)$ & 29,24 & 28,86 & 28,45 & 29,24 & 5,22 & $\hat{Y}^{n s}=22,95$ \\
\hline \multicolumn{7}{|c|}{ Tarde } \\
\hline $\mathrm{FR}(\mathrm{r} / \mathrm{min})$ & 81,12 & 104,67 & 106,00 & 85,12 & 13,74 & $\hat{Y}=-0,01 X^{2}+1,04 X+81,12$ \\
\hline $\operatorname{TR}\left({ }^{\circ} \mathrm{C}\right)$ & 39,32 & 39,08 & 39,18 & 39,26 & 0,82 & $\hat{Y}^{n s}=39,21$ \\
\hline FC (bat/min) & 112,80 & 112,8 & 103,2 & 96,00 & 19,59 & $\hat{Y}^{n s}=106,20$ \\
\hline $\mathrm{TC}\left({ }^{\circ} \mathrm{C}\right)$ & 28,37 & 30,39 & 30,22 & 31,14 & 4,08 & $\hat{Y}^{n s}=30,03$ \\
\hline
\end{tabular}

$\mathrm{CV}=$ Coeficiente de variação. ${ }^{\text {ns }=}$ não significativa.

ram teores próximos de fibra e o consumo de MS foi semelhante em função dos níveis de substituição da torta.

$\mathrm{O}$ consumo de EE aumentou linearmente $(\mathrm{p}<0,05)$ com a substituição do farelo de soja pela torta de amendoim. Esse resultado já era esperado, pois como a torta de amendoim apresenta maiores teores de EE do que o farelo de soja, elevando assim, o EE das dietas, e aliado ao fato de não ter comprometido o consumo de MS, esse aumento resultou no aumento do consumo de EE pelos animais (tabela IV).Os consumos de NDT foram semelhantes $(p>0,05)$ com a inclusão da torta, devido aos teores desta fração serem próximos entre as dietas, além dos cordeiros terem ingerido quantidades das frações digestíveis de PB, FDN e CNF semelhantes, com exceção do EE que mesmo apresentando um efeito linear positivo, não foi suficiente para resultar em elevação nos teores de NDT consumidos.

Os coeficientes de digestibilidade da MS, FDN e CNF não apresentaram diferenças $(p>0,05)$ na substituição do farelo de soja pela torta de amendoim (tabela V). A digestibilidade da MS foi semelhante entre as dietas e esse fato pode ter ocorrido devido à composição química dos concentrados nas dietas, serem semelhantes e o consumo do alimento similar entre os tratamentos, não modificando a digestibilidade, o que corrobora com Queiroz et al. (2010), e Silva et al. (2015) que trabalhando com com torta de amendoin em substituição ao farelo de soja também não observaram efeito na digestibilidade desses nutrientes.

A digestibilidade da FDN não apresentou diferenças $(p>0,05)$ com a inclusão da torta de amendoim, mesmo o aumento dos teores de EE entre as dietas não comprometeu a digestibilidade dos compostos fibrosos. Geralmente, um aumento do teor de lípidos na dieta tende a comprometer a digestão dos componentes fibrosos. No entanto, Doreau e Chilliard (1997b) relataram que a adição de lípidos em concentrações de até $5 \%$ de EE na dieta tiveram efeitos mínimos sobre a digestão de carboidratos.

A digestibilidade da PB apresentou um efeito quadrático $(\mathrm{p}<0,01)$, a análise de regressão mostrou que o menor valor de digestibilidade da PB foi de $80,91 \%$ 
na dieta com 59,45\% de torta de amendoim em substituição ao farelo de soja.

Quanto ao EE, o aumento nos teores das dietas e no consumo permitiu um efeito linear crescente $(p<0,01)$ na digestibilidade deste nutriente (tabela V). Segundo Palmquist (1991), o aumento no consumo de EE compensa a perda de lipídios endógenos, resultando em aumento na digestibilidade aparente. Este efeito também Foi observado por Silva et al. (2015).

As atividades de alimentação, ruminação e ócio não foram influenciadas $(\mathrm{p}>0,05)$ pelos níveis de torta de amendoim em substituição ao farelo de soja nas dietas (tabela VI).

A similaridade no consumo de matéria seca (tabela III) e no tempo ingerindo alimentos e ruminando (tabela VI), provavelmente está relacionado à composição dos teores de fibras da dieta e o estímulo do fornecimento das dietas e também, como mencionado anteriormente, a aceitabilidade pelos animais, pois não foi observado seleção dos alimentos no momento da ingestão. Hubner et al. (2009), afirmam que o incremento do nível de FDN na dieta afetou o consumo de matéria seca, com reflexos diretamente proporcionais sobre os tempos de ingestão e ruminação e inversamente proporcionais sobre o tempo de ócio dos animais, porém nesse experimento os teores de fibra foram semelhantes não interferindo no tempo de ingestão e ruminação.

Observou-se que não houve efeito $(p>0,05)$ das dietas sobre a frequência cardíaca (FC), temperatura retal (TR) e temperatura corpórea (TC) (tabela VI). Estes parâmetros foram semelhantes no período da manhã e tarde, exceto para a frequência respiratória que no período da tarde que apresentou um efeito quadrático $(\mathrm{p}<0,05)$. O ponto máximo de inclusão da torta de amendoim foi de $52 \%$, com uma frequência respiratória de 108,16 por minuto (tabela VI).

A substituição do farelo de soja pela torta de amendoim, não reduziu os teores de carboidratos não fibrosos e não havendo redução desse nutriente, os carboidratos não fibrosos no rúmen foram fermentados e a produção de calor no organismo animal pode ter permanecido constante, e com isso a frequência cardíaca dos animais no período da manhã foi semelhante com a substituição da dieta. Na parte da tarde pode ser explicado pelo aumento da temperatura neste período.

A frequência cardíaca foi semelhante nas dietas em que houve a inclusão da torta de amendoim o que não interferiu no bem estar animal, nem ocasionou alterações de funcionalidade física.

\section{CONCLUSÃO}

A substituição do farelo de soja pela torta de amendoim pode ser recomendada, como uma alternativa na confecção de concentrados, substituindo totalmente o farelo de soja na alimentação de cordeiros, sem prejuízos ao consumo, digestibilidade e parâmetros fisiológicos dos animais.

\section{BIBLIOGRAFIA}

Abdalla, A.L.; Silva Filho, J.C.; Godoi, A.R; Carmo, C.A. e Eduardo, J.L.P. 2008. Utilização de subprodutos da indústria de biodiesel na alimentação de ruminantes. Rev Bras Zootecn, 37: 260-258.

AOAC. (Association of Official Analytical Chemists). 1990. Official methods of analysis. $15 \mathrm{ed}$. AOAC. Washington.

Buffington, D.E.; Collazo Arocho, A.; Canton, G.H. and Pitt, D. 1981. Black globe humidity ndex (BGHI) as a comfort equation for dairy cows. Trans ASAE, 24: 711-714.

Doreau, M. and Chilliard, Y. 1997a. Effects of ruminal or postruminal fish oil supplementation on intake and digestion in dairy cows. Reprod Nutr Dev, 37: 113-124. doi:10.1051/rnd:19970112.

Forbes, J.M. 1995. Voluntary food intake and diet selection in farm animals. $C A B$ International. Wallingford. $532 \mathrm{pp}$.

Huebner, B.; Dwyer, S. and Hauser, M.D. 2009. The role of emotion in moral psychology. Trends Cogn Sci, 13: 1-6.

Johnson, T.R. and Combs, D.K. 1991. Effects of prepartum diet, inert rumen bulk, anddietary polyethylene glycol on dry matter intake of lactating dairy cows. J Dairy Sci, 74: 933-944.

Lage, J.F.; Paulino, P.V.R.; Pereira, L.G.R.; Valadares Filho, S.C.; de Oliveira, A.S.; Detmann, E.; Souza, N.K.P. e Lima, J.C.M. 2012. Glicerina bruta na dieta de cordeiros terminados em confinamento. Pesqui Agropecu Bras, 45: 1012-1020.

NRC. National Research Council. 2001. Nutrient requirements of dairy cattle. 7 ed. rev. National Academy of Science. Washington. 381 pp.

NRC. National Research Council. 1994. Nutrient requirements of poultry. 9 ed. National Academy of Science. Washington. 155 pp.

Palmquist, D.L. 1991. Influence of source and amount of dietary fat on digestibility in lactating cows. J Dairy Sci, 74: 1354-1360.

Queiroz, M.A.A.; Susin, I.; Pires, A.V.; Ferreira, E.M.; Mendes, C.Q. e Mourão, G.B. 2010. Características físico-químicas de fontes protéicas e suas interações sobre a degradação ruminal e a taxa de passagem Rev Bras Zootecn, 39: 1587-1594.

Santos, V.C.; Ezequiel, J.M.B.; Morgado, E.S.; Homem Júnior, A.C.; Fávaro, V.R.; D'Aurea, A.P.; Souza, S.F. e Barbosa, J.C. 2012. Influência de subprodutos de oleaginosas sobre parâmetros ruminais e a degradação da matéria seca e da proteína bruta. Arq Bras Med Vet Zoo, 64: 1284-1291.

Silva, T.M; Medeiros, A.N.; Oliveira, R.L.; Neto, S.G.; Ribeiro, M.D.; Bagaldo, A.R. and Ribeiro, O.L. 2015. Peanut cake as a substitute for soybean meal in the diet of goats. J Anim Sci, 93: 2998-3005.

Sniffen, C.J; O'Connor, J.D.; Van Soest, P.J.; Fox D.G. and Russell, J.B. 1992. A net carbohydrate and protein system for evaluating cattle diets: II. Carbohydrate and protein availability. J Anim Sci, 70: 3562-3577.

Van Soest, P.J.; Robertson, J.B. and Lewis, B.A. 1991. Symposium: carbohydrate methodology, metabolism, and nutritional implications in dairy cattle. J Dairy Sci, 74: 3583-3597.

Van Soest, P.J. 1994. Nutritional ecology of the ruminant. Cornell University Press. Ithaca, NY. 476 pp.

Vasconcelos, J.T. and Galyean, M.L. 2007. Nutritional recommendations of feedlot consulting nutritionists: The Texas Tech University Survey. $J$ Anim Sci, 85: 2772-2781. 